\title{
Polish Society of Gynecologists and Obstetricians Recommendations on diagnosis and management of fetal growth restriction
}

\author{
Sebastian Kwiatkowski ${ }^{1}$, Andrzej Torbe ${ }^{1}$, , Dariusz Borowski ${ }^{2}\left(\mathbb{D}\right.$, Grzegorz Breborowicz $^{3}$, \\ Krzysztof Czajkowski ${ }^{4}{ }^{\oplus}$, Hubert Huras ${ }^{5}{ }^{\oplus}$, Anna Kajdy ${ }^{6}$, Jaroslaw Kalinka ${ }^{7}$, \\ Katarzyna Kosinska-Kaczynska ${ }^{8}$,, Bozena Leszczynska-Gorzelak ${ }^{9}$, Wojciech Rokita ${ }^{10}$, \\ Mariola Ropacka-Lesiak ${ }^{3}$, Piotr Sieroszewski ${ }^{11}$ (D) , Miroslaw Wielgos ${ }^{12}$ (), Mariusz Zimmer ${ }^{13}$ (D) \\ ${ }^{1}$ Clinical Department of Obstetrics and Gynecology, Pomeranian Medical University, Szczecin, Poland \\ ${ }^{2}$ Clinic of Fetal-Maternal, Gynecology and Neonatolgy, Collegium Medicum, \\ Nicolaus Copernicus University in Bydgoszcz, Poland \\ ${ }^{3}$ Department of Perinatology and Gynecology, Poznan University od Medical Sciences, Poland \\ ${ }^{4} 2^{\text {nd }}$ Department of Obstetrics and Gynecology, Medical University of Warsaw, Poland \\ ${ }_{5}^{5}$ Jagiellonian Univeristy Collegium Medicum, Department of Obstertics and Perinatology, Cracow, Poland \\ ${ }^{6}$ Department of Reproductive Health, Centre of Postgraduate Medical Education, Warsaw, Poland \\ ${ }^{7}$ Department of Perinatology, Medical University of Lodz, Poland \\ $82^{\text {nd }}$ Department of Obstetrics and Gynecology, Center of Postgraduate Medical Education, Warsaw, Poland \\ ${ }^{9}$ Chair and Department of Obstetrics and Perinatology, Medical University of Lublin, Poland \\ ${ }^{10}$ Department and Clinic of Obstetrics and Gynaecology, Collegium Medicum Jan Kochanowski University in Kielce, Poland \\ ${ }^{11}$ Department of Obstetrics and Gynecology, Medical University of Lodz, Poland \\ ${ }^{12} 1^{\text {st }}$ Chair and Department of Obstetrics and Gynecology, Medical University of Warsaw, Poland \\ ${ }^{13} 2^{\text {nd }}$ Department of Gynecology and Obstetrics, Wroclaw Medical University, Wroclaw, Poland
}

Recommendations present the current management, that may be modified and changed in certain cases, after a thorough analysis of a given clinical situation, which in the future may be the basis for their modification and actualization.

\section{SUMMARY OF THE RECOMMENDATIONS Definitions \\ Fetal Growth Restriction (FGR) — a synonim for intrauterine growth restriction (IUGR)}

$<32$ weeks - early-onset FGR; > 32 - late onset FGR Hypotrophy - a term related to a newborn with growth restriction

\section{Risk factors}

Risk factors of growth restriction should be assessed in every woman at the beginning of pregnancy and at each following visit (Tab. 1A and 1B). Increased risk of FGR is diagnosed if, at least one major or three minor risk factors are present. Risk may also be determined using an algorithm combining ultrasound, medical history, and serum markers.

\section{Confirming the gestational age}

Each pregnant woman should undergo an ultrasound examination between $11-13+6$ weeks of gestation, during which the crown-rump length is measured, and the date of delivery is determined. If there is no ultrasound examination at this time, the delivery date should be determined on the basis of $\mathrm{HC}$ and FL measurements in the second trimester of pregnancy.

\section{Differential diagnosis}

Suspicion of abnormal growth should be followed by a detailed work up to determine the potential cause (chromosomal abnormalities, infections, congenital anomalies, impaired blood flow in the uterine arteries, changes in the placenta).

\section{Growth assessment}

The recommended method of calculating the estimated fetal weight is the Hadlock equation. AC and HC measurements should be made using an ellipse to cover the outer contours of the abdomen and fetal head. Based on availability and accessibility, PSOGO recommends the use of 
Table 1A. Major risk factors for fetal growth restriction (adapted from RCOG - 13)

\begin{tabular}{|c|c|c|}
\hline \multirow{9}{*}{ Maternal } & Antiphospholipid syndrome & RR $6.2(2.4-16.0)$ \\
\hline & Diabetes-related angiopathy & OR $6(1.5-2.3)$ \\
\hline & Renal insufficiency & AOR $5.3(2.8-10)$ \\
\hline & Intense physical activity & AOR $3.3(1.5-7.2)$ \\
\hline & $>40$ years of age & OR $3.2(1.9-5.4)$ \\
\hline & Cocaine & OR $3.2(2.4-4.3)$ \\
\hline & Maternal birthweight $<10$ centile & OR $2.6(2.3-3.0)$ \\
\hline & Chronic hypertension & ARR $2.5(2.1-2.9)$ \\
\hline & Smoking $>10$ cigarettes/day & OR $2.2(2.0-2.4)$ \\
\hline Obstetric history & Birth of neonate with birthweight $<10$ percentile & OR $3.9(2.1-7.1)$ \\
\hline \multirow{4}{*}{ Current pregnancy } & Pre-eclampsia & AOR $2.7(1.2-4.3)$ \\
\hline & Threatened abortion accompanied by menstrual-like bleeding & AOR $2.6(1.2-5.6)$ \\
\hline & Pregnancy-induced hypertension - severe & RR $2.5(2.3-2.8)$ \\
\hline & Hyperechogenic bowel of the fetus in II trimester on ultrasound & AOR $2.1(1.5-2.9)$ \\
\hline Paternal & Paternal birthweight $<10$ percentile & OR $3.5(1.3-10.3)$ \\
\hline
\end{tabular}

$\mathrm{RR}$ - relative risk; $\mathrm{OR}$ — odds ratio; $\mathrm{AOR}$ - adjusted odds ratio

Table 1B. Minor risk factors for FGR (adapted from RCOG - 13)

\begin{tabular}{|c|c|c|}
\hline \multirow{7}{*}{ Maternal } & Primiparity & OR $1.9(1.8-2.0)$ \\
\hline & Diet low in fruit before pregnancy & AOR $1.9(1.3-2.8)$ \\
\hline & IVF & OR $1.6(1.3-2.0)$ \\
\hline & Obesity BMI $\geq 30$ & RR $1.5(1.3-1.7)$ \\
\hline & Maternal age $>35$ years & OR $1.4(1.1-1.8)$ \\
\hline & Underweight $\mathrm{BMI}<20$ & OR $1.2(1.1-1.3)$ \\
\hline & Overweight BMI 25-29.9 & RR $1.2(1.1-1.3)$ \\
\hline \multirow{3}{*}{ Obstetric history } & Mild pre-eclampsia & AOR $1.3(1.2-1.4)$ \\
\hline & Time between pregnancies $<6$ months & AOR $1.3(1.9-1.3)$ \\
\hline & Time between pregnancies $\geq 60$ months & AOR $1.3(1.2-1.4)$ \\
\hline \multirow{2}{*}{ Current pregnancy } & Caffeine consumption $\geq 300 \mathrm{mg} /$ daily in the III trimester & OR $1.9(1.3-2.8)$ \\
\hline & Pregnancy-induced hypertension - mild & RR $1.3(1.3-1.4)$ \\
\hline
\end{tabular}

$\mathrm{RR}$ - relative risk; $\mathrm{OR}$ — odds ratio; $\mathrm{AOR}$ — adjusted odds ratio; IVF — in vitro fertilisation; $\mathrm{BMI}$ — body mass index

the Hadlock growth charts until the development and dissemination of growth standards for the Polish population.

Fundal height assessment should be performed in low-risk pregnancies starting from the $24^{\text {th }}$ week of gestation.

\section{Diagnosis and management}

We recommend FGR diagnosis based on ultrasound criteria reported in the Delphi consensus. After the diagnosis, management is always individualized, and surveillance should incorporate all the available tools. Management is feasible in an outpatient setting. Hospitalization is indicated if FGR is accompanied by:

- oligohydramnios
- abnormal CTG tracings

- abnormal biophysical profile

- vaginal bleeding

- reduced or rapid fetal movements

- absent or reversed end diastolic flow in the umbilical artery

- $\quad \mathrm{CPR}<5$ percentile

- absent or reversed end diastolic flow in the ductus venous

- other symptoms of fetal distress

\section{Delivery}

Choice of timing and mode of delivery depends on the severity of FGR, accompanying abnormalities in CTG trac- 


\begin{tabular}{|l|l|l|}
\hline \multicolumn{2}{|l}{ Table 2. Comparison of early vs late fetal growth restriction } \\
\hline & Early FGR & Late FGR \\
\hline Main problem & Management & Diagnosis \\
\hline Placental changes & $>30 \%$ & $<30 \%$ \\
\hline Cardiovascular reaction to hypoxia & Adaptation & No adaptation \\
\hline Tolerance of hypoxia & Natural history of disease established & Low \\
\hline Perinatal mortality & High, especially $<26$ weeks of pregnancy & Low \\
\hline Perinatal morbidity & High, especially $<26$ weeks of gestation & $\begin{array}{l}\text { Increased risk of perinatal complications. Risk of neonatal, } \\
\text { childhood and adult morbidity unknown. }\end{array}$ \\
\hline
\end{tabular}

FGR - fetal growth restriction

ings and ultrasound assessment. In the absence of previous indications, delivery is recommended not later than week 37.

\section{ABBREVIATIONS AND DEFINITIONS}

AC - abdominal circumference

AEDV - absent end diastolic velocity

AGA - appropriate for gestational age - fetuses and neonates with estimated fetal weight and neonatal weight between the 10-90 percentile

AOR - adjusted odds ratio

APLS - antiphospholipid syndrome

ARR - adjusted relative risk

BMI — body mass index

BPD - biparietal diameter

CPR - cerebro-placental ratio

CRL — crown-rump-length

DV - Ductus Venous

Early-onset FGR - early onset growth restriction, onset before 32 weeks of gestation

FGR - fetal growth restriction - is the failure of the fetus to achieve the programmed birth weight after excluding internal factors (chromosomal aberrations, infections, birth defects)

FL - femur length

HC - head circumference

Hypotrophy - a term related to a newborn born with growth restriction

IUGR - intrauterine growth restriction - synonym of FGR Late-onset FGR — late onset fetal growth restriction, onset after 32 weeks of gestation

LGA - large for gestational age - fetuses and neonates with estimated fetal weight and neonatal weight above the 90 centile

MCA - middle cerebral artery

OR - odds ratio

PIGF - placental growth factor

REDV - reverse end diastolic velocity

$\mathbf{R} \mathbf{R}$ - relative risk
SGA — small-for-gestational-age - fetuses with estimated weight (EFW) on ultrasound between the $3^{\text {rd }}$ and $10^{\text {th }}$ percentile for gestational age without signs of growth failure or newborns with birth weight below the $10^{\text {th }}$ percentile TORCH -Toxoplasmosis, Rubella, Cytomegalovirus, Herpes simplex

UA - umbilical artery

UtA - uterine artery

ARSA - aberrant right subclavian artery

\section{AIM}

The aim of these recommendations is to present FGR management principles based on currently available scientific evidence and clinical experience.

\section{INTRODUCTION}

Fetal Growth Restriction (FGR) is a clinical situation in which the fetus does not reach its programmed birth weight [1]. Currently, there are two types of fetal growth restriction. Early-onset FGR before 32 weeks of gestation. Early FGR often coexists with maternal hypertension or connective tissue disease [2]. In the TRUFFLE study, pre-eclampsia was found in $75 \%$ of pregnancies included in the study [3]. Early FGR is an indication to refer the patient to a higher reference level and is primarily a challenge in terms of planning appropriate management. The natural course of the disease is relatively well understood. The GRIT and TRUFFLE studies analyzed the effectiveness of various diagnostic and therapeutic regimens and their impact on the outcomes of perinatal care (both early and late) [3-5]. According to experts, much more controversy exists around late FGR, which is defined as growth restriction that occurs after 32 weeks of gestation. In these cases, the primary problem is diagnosis in low-risk pregnancies, as in many countries, third trimester ultrasound examination in this group of women is not recommended (Tab. 2). FGR detection in low-risk pregnancies in many countries does not exceed $15 \%[2,6,7]$. In Poland, it is currently recommended to perform an ultrasound scan in the third trimester 
between 28-32 weeks of pregnancy and at term [8, 9]. In Poland, despite routine performance of the third trimester ultrasound, this detection rate is not much higher [10]. One of the greatest challenges of modern perinatology is the prevention of intrauterine deaths [11]. The experience from Great Britain shows that the identification of women with an increased risk of growth failure, staff training, the introduction of diagnostic and therapeutic recommendations and guidelines gives a chance to reduce perinatal mortality [12].

\section{Risk factors}

Risk factors for growth restriction should be assessed in every woman at the beginning of pregnancy and at each following visit. FGR risk factors can be classified as major or minor depending on the OR, AOR or RR (Tab. 1A and 1B). These are risk factors identified on the basis of maternal history and the course of current pregnancy. The diagnosis of an increased risk of FGR is based on the presence of at least one major risk factor or three minor risk factors [13]. The screening tests and preventive measures are described in detail later in the recommendations. A high risk of FGR in the first trimester of pregnancy is an indication to consider prophylactic administration of acetylsalicylic acid [14].

Pregnant women in Poland rarely admit to smoking. It is also difficult to obtain reliable information regarding their home exposure to cigarette smoke. According to data published for the Polish population, $12 \%$ of women continue to smoke during pregnancy [15]. Therefore, the risk should not be differentiated depending on the number of cigarettes smoked or the environmental exposure. If the patient reports that she had stopped smoking in the first trimester, we classify it as a major risk factor of FGR.

\section{DIAGNOSIS AND MANAGEMENT} Differential diagnosis Confirmation of gestational age

The basic criterion for the assessment and diagnosis of growth abnormalities is the correct determination of the duration of pregnancy. Measuring the CRL between 8 and 14 weeks of gestation is considered the most accurate method of assessing the duration of pregnancy [16]. Currently, according to the PSOGO recommendations, every pregnant woman should undergo an ultrasound examination between 11-13+6 weeks of gestation. In such a case, the measurement of the crown-rump length should be performed, and the date of delivery be determined on its basis. If the duration of pregnancy has been determined at that time, it should not be recalculated on the basis of subsequent ultrasound examinations. [8]. If data on CRL is unavailable, then the $\mathrm{HC}$ and FL measurements can be used to determine the duration of pregnancy in the second trimester [16].

\section{Risk assessment of chromosomal abnormalities}

One third of early-onset FGR may coexist with chromosomal abnormalities or genetic syndromes [17]. Therefore, if FGR is diagnosed before 24 weeks of gestation, the risk of chromosome aberrations should be verified. A detailed interview regarding what genetic and screening tests have been performed so far by the patient is helpful. The medical documentation should include an annotation whether the first trimester screening was performed in accordance with the recommendations of PSOGO. If not - it should be noted in the documentation whether this was discussed and offered to the patient.

The indications for invasive genetic testing in the case of FGR are as follows:

- Early FGR < 24 weeks

- Major structural defects accompanying FGR

- Presence of benign ultrasound markers indicating an increased risk of aneuploidy (nuchal fold thickening, ventriculomegaly, ARSA, choroid plexus cysts, incorrect hand position, septal defects, hyperechogenic bowel, shortened humerus, hypoplastic nasal bone $<10$ percentile).

If the ultrasound examination does not show signs of placental insufficiency, and the patient has not had the first trimester screening in accordance with the FMF and PSOGO standards, or if, despite being at high risk, further screening was not performed (free fetal DNA testing), then amniocentesis or cordocentesis should be offered.

\section{Diagnosis of TORCH infections}

FGR suspicion should prompt diagnosis of cytomegaly, toxoplasmosis, rubella and herpes simplex. In Poland, routine malaria diagnosis is not recommended, although in selected cases, justified by medical history, it may be suggested.

Invasive diagnosis to confirm fetal infection should be considered individually. Amniocentesis should not be performed before 18 weeks of gestation and not earlier than 4 weeks after the onset of maternal symptoms. The indications for amniocentesis can be both the results of serological tests (the presence of specific lgM and IgG antibodies with low avidity of IgG antibodies) [18], as well as ultrasound assessment performed by an experienced professional or in a dedicated prenatal diagnosis center (cerebral, liver microcalcifications, ventriculomegaly, microcephaly, hepatomegaly, effusion in body cavities, fetal edema and placentomegaly) [19].

\section{Anatomy assessment}

FGR is an indication for a detailed assessment of fetal anatomy. The scope of ultrasound workup depends on the gestational age. Estimated fetal weight below the 3rd per- 


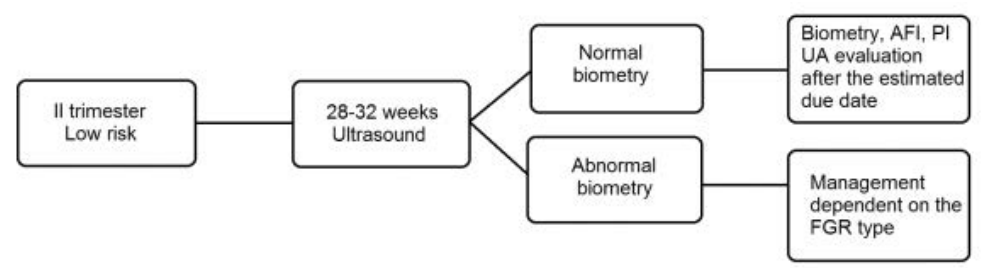

Figure 1. Low-risk pregnancy

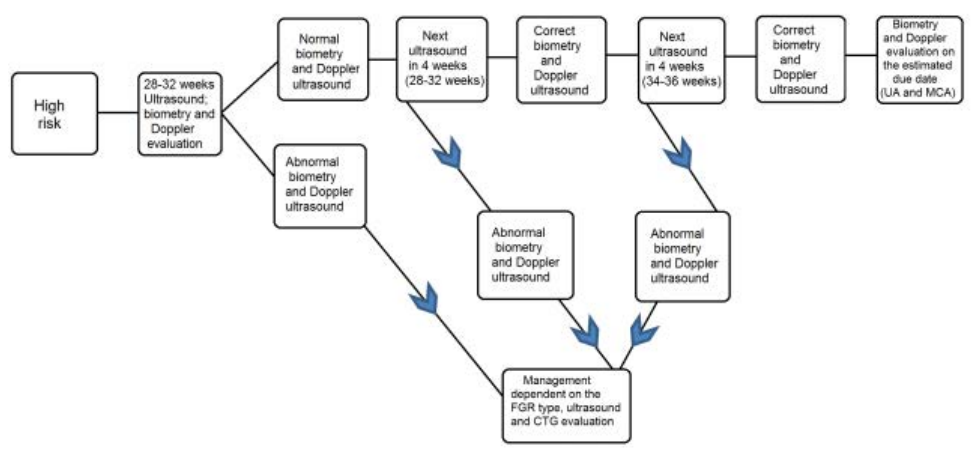

Figure 2. High-risk pregnancy

centile should include a detailed heart and central nervous system evaluation.

\section{Growth assessment}

In a low-risk pregnancy, fetal growth should be assessed at week 20-22; 28-32 weeks and after 40 weeks, in accordance with the current standard of perinatal care and the PSOGO recommendations [8, 9] (Fig. 1). In a high-risk pregnancy, fetal growth should be assessed: at week 20-22; at week 26-28; at week 34-38 and week 40 [8] (Fig. 2). In the case of FGR diagnosis, the frequency of ultrasound examinations depends on the severity of growth restriction. Fetal weight assessment should be made in accordance with the Hadlock II methodology, considering the BPD, HC, AC and FL measurements. The $\mathrm{AC}$ and $\mathrm{HC}$ measurements should be made using an ellipse and cover the external outline of the fetal soft tissues [16].

When assessing the fetal growth, the use of population growth charts is recommended [20]. The Z-score can also be used, but the percentile method is more readable for the recipients [21].

An alternative are customized growth charts, which allow calculation of the optimal birth weight for a given pregnancy, accounting for the mother's ethnic origin, her height and weight before pregnancy and parity [22]. However, in the light of previous reports, they do not demonstrate a predictive advantage. At the time of delivery, nearly $70 \%$ of fetuses with weight estimated between the $3^{\text {rd }}$ and $10^{\text {th }}$ centile is healthy, and their weight is exclusively constitu- tional (maternal constitutional conditions, race, fertility, BMI) [23]. When assessing the weight of the fetus and its centile, it is always worth paying attention to which specific measured parameter is responsible for the diagnosis of FGR. A low fetal weight percentile can sometimes be due to, for example, a relatively "shorter" FL measurement and may result in an unnecessary implementation of intensive care and invasive measures. At present, there are no recommendations to use customized growth charts for a given population, although it may be a more appropriate diagnostic method in the future [16]. Due to availability, PSOGO recommends using the Hadlock II algorithm until Polish population standard is developed and disseminated.

\section{Fundal height measurement}

The fundal height measurement is an approximate method of assessing the stage of pregnancy and the size of the fetus. The result is influenced by maternal obesity, parity and the obstetrician's experience. The assessment of fundal height can only be used as an indication for ultrasound assessment. It can be performed in low-risk pregnancies starting from the $24^{\text {th }}$ week of gestation. It involves measuring the distance between the upper edge of the pubic symphysis and the floor of the uterus (SF, symphysis-fundal). The values and standard deviations of fundal height for a given gestational age according to Intergrowth are presented in Table 3. FGR is suspected when the SF measurement value is lower by 3 or more than 3 centimeters for a given gestational age [24]. This is an indication for an ultrasound 


\begin{tabular}{|c|c|c|}
\hline $\begin{array}{l}\text { Gestational age } \\
\text { [weeks] }\end{array}$ & $\begin{array}{l}\text { Symphysis-fundal } \\
\text { height (SF) } \\
\text { [cm] }\end{array}$ & $\begin{array}{l}\text { Fundal height - } \\
\leq 2 \text { standard deviation } \\
\text { (SF }-\leq 2 S D)[\mathrm{cm}]\end{array}$ \\
\hline 24 & 23.8 & $\leq 20.5$ \\
\hline 25 & 24.7 & $\leq 21.5$ \\
\hline 26 & 25.7 & $\leq 22.4$ \\
\hline 27 & 26.7 & $\leq 23.3$ \\
\hline 28 & 27.7 & $\leq 24.3$ \\
\hline 29 & 28.6 & $\leq 25.2$ \\
\hline 30 & 29.6 & $\leq 26.1$ \\
\hline 31 & 30.5 & $\leq 26.9$ \\
\hline 32 & 31.4 & $\leq 27.8$ \\
\hline 33 & 32.3 & $\leq 28.6$ \\
\hline 34 & 33.2 & $\leq 29.5$ \\
\hline 35 & 34.0 & $\leq 30.3$ \\
\hline 36 & 34.9 & $\leq 31.0$ \\
\hline 37 & 35.7 & $\leq 31.8$ \\
\hline 38 & 36.5 & $\leq 32.5$ \\
\hline 39 & 37.2 & $\leq 33.2$ \\
\hline 40 & 38.0 & $\leq 33.9$ \\
\hline 41 & 38.7 & $\leq 34.6$ \\
\hline 42 & 39.3 & $\leq 35.2$ \\
\hline
\end{tabular}

\begin{tabular}{|c|c|}
\hline $\begin{array}{l}\text { Early FGR } \\
\text { Gestational age } \leq 32 \text { weeks }\end{array}$ & $\begin{array}{l}\text { Late FGR } \\
\text { Gestational age }>32 \text { weeks }\end{array}$ \\
\hline $\begin{array}{l}\text { AC or EFW }<3 \text { percentile or } \\
\text { UA-AEDF }\end{array}$ & AC or EFW $<3$ percentile \\
\hline or & or $2 / 3$ of criteria below \\
\hline $\begin{array}{l}\text { 1. AC or EFW }<10 \text { centile and } \\
\text { 2. UtA-PI }>95 \text { centile and/or } \\
\text { 3. UA-PI }>95 \text { centile }\end{array}$ & $\begin{array}{l}\text { 1. AC or EFW }<10 \text { centile } \\
\text { 2. AC or EFW drop }>2 \text { quartile } \\
\text { on the growth chart * } \\
\text { 3. CPR }<5 \text { centile or UA- } \\
\mathrm{PI}>95 \text { percentile }\end{array}$ \\
\hline
\end{tabular}

*percentiles are not individualized, individual measurements of the fetus should be analyzed in each case of a low percentile; FGR - fetal growth restriction; $A C$ - abdominal circumference; $A E D F-$ no diastolic flow; $C P R$ - cerebroplacental ratio; EFW - Estimated Fetal Weight; $\mathrm{PI}$ — pulsation indicator; $\mathrm{UA}$ - umbilical artery; UtA - uterine artery

examination. Fundal height assessment is not indicated in patients with pre-pregnancy BMI > 35 and in women with large uterine fibroids.

\section{Delphi Criteria for FGR}

In 2016, in order to standardize the diverse nomenclature, a definition of FGR was developed through an international consensus. This definition applies to fetuses with placental growth failure, after excluding congenital abnormalities, TORCH infections and chromosomal abnormalities. Fetal growth restriction has been classified into early and late onset FGR. The diagnostic criteria are presented in Table 4 [25].

As a rough measure, early-onset fetal growth restriction begins before 32 weeks of gestation. For diagnosis, one of the following parameters must be identified:

- abdominal circumference (AC) measured by ultrasound $<3$ percentile at a given gestational age,

- estimated fetal weight (EFW) measured by ultrasound $<3$ percentile at a given gestational age,

- absent umbilical artery end-diastolic flow (UA AEDV) regardless of the estimated fetal weight.

The last of the above-mentioned parameters indicates impaired placental flow, which allows to distinguish a group of children with potentially impaired growth in the following weeks of gestation. Early-onset FGR may also be suspected when $\mathrm{AC}$ or EFW are lower than the $10^{\text {th }}$ centile at a given gestational age, and the umbilical artery (UA) and/or uterine artery (UtA) pulsation index (PI) is greater than the $95^{\text {th }}$ centile at a given gestational age.

Late-onset fetal growth restriction begins after 32 weeks of gestation. The diagnosis is made by the occurrence of a single parameter:

- - abdominal circumference (AC) as measured by ultrasound $<3$ centile for a given gestational age

- estimated fetal weight $(E F W)<3$ centile for a given gestational age.

The diagnosis of late FGR can also be made when the estimated fetal weight or abdominal circumference is below the $10^{\text {th }}$ percentile and at least one of the following criteria is met: - growth inhibition above 2 quartiles (more than 50 centiles)

- CPR value (quotient of $\mathrm{PI}$ in MCA and $U A$ ) $<5$ percentile for a given gestational age

- UA PI > 95 percentile for a given gestational age

As in the case of early FGR, the last two of the above-mentioned parameters indicate the beginning of possible fetal hypoxia, brain-sparing and impaired placental flow, i.e. they allow for identification of the group of children with potentially impaired growth in the following weeks of pregnancy.

\section{Early fetal growth restriction}

The management of early FGR, the frequency of fetal monitoring and the route of delivery depends on severity of the disease. In the TRUFFLE study, which compared computer CTG analysis and the assessment of Doppler blood flow values in DV in monitoring the well-being of the fetus, $85 \%$ of children in the second year of life had no neurological complications, and only $1 \%$ had cerebral palsy [4]. The most important risk factor for neonatal complications, including 
death, was prematurity. The rate of neurological complications was maintained at similar level regardless of the gestational age, but it was significantly lower in the study group where interventions were based on the blood flow in ductus venosus. The highest risk of intrauterine death regarded fetuses with FGR diagnosed before 26 weeks of gestation. Each day of intrauterine life between 26-29 weeks of gestation increases the chances of proper development by about $2 \%$, while between $30-34$ only by $1 \%$ [26]. There are 4 stages of early FGR [27]. Establishing the diagnosis requires a change in the supervision method and performing fetal biometry, assessment of the amniotic fluid volume and assessment of the blood flow in Doppler examination (UtA, UA, MCA and $D V)$. The indications for termination of pregnancy consist of abnormal values of ultrasound indicators, CTG parameters and/or progressing symptoms of pre-eclampsia.

\section{Stage I}

Stage $\mathrm{I}$ is diagnosed when the estimated fetal weight or abdominal circumference are below the 3rd percentile or when the fetal weight is between the $3-10^{\text {th }}$ centile, with an increased uterine artery pulsatility index (mean $\mathrm{PI}>95^{\text {th }}$ centile or $\mathrm{CPR}<5^{\text {th }}$ centile or MCA $<5^{\text {th }}$ centile). In this case, the blood flow should be assessed once a week together with an assessment of the amniotic fluid volume, and from 34 weeks of gestation, a CTG should be performed once a week. Fetal weight should not be assessed more frequently than every 2 weeks. If the cerebroplacental ratio (CPR) is above the $5^{\text {th }}$ centile, there is no need for an assessment of the ductus venous (DV) blood flow. If, however, it is below the 5 th centile, the blood flow in DV should be assessed. Normal values are $<95$ centile. The most important factor in predicting the fetus well-being in CTG is the assessment of short-term variability (STV) over a period of 40-60 minutes. Amniotic fluid volume can be assessed using both the maximum vertical pocket (MVP) and the amniotic fluid index (AFI). An incorrect MVP value is $<2 \mathrm{~cm}$, and an incorrect $\mathrm{AFI}$ index $<5 \mathrm{~cm}$.

\section{Stage II}

Stage II is diagnosed in the absence of end-diastolic flow in the umbilical cord. It is estimated that the risk of intrauterine death in the absence of end-diastolic flow in the umbilical cord is more than three times increased $-\mathrm{OR}=3.59$, with a $95 \% \mathrm{Cl}$ 2.29-5.62 [28]. This is an indication for urgent hospitalization of the patient. It is optimal to implement intensive cardiotocographic monitoring. Ultrasound examination should be performed 2-3 times a week. Blood flow in UtA, UA, MCA and DV is evaluated. CPR $<5^{\text {th }}$ percentile and $M C A<5^{\text {th }}$ percentile, therefore symptoms of circulatory centralization, which are only adaptive symptoms of the fetus, are not an indication for termination of pregnancy.
Persistence of the lack of late-diastolic blood flow is an indication for the administration of steroids and increased CTG surveillance. If during observation there is an absent a-wave or there is a reversed a-wave in the ductus venosus, then it is an indication for an immediate termination of pregnancy - the risk of death in this situation is $\mathrm{OR}=12.39$, with a $95 \% \mathrm{Cl}$ 8.49-18.06. In other cases, cardiotocographic supervision should be performed daily. With correct CTG, pregnancy should be ended after 34 weeks of gestation, after a previous steroid therapy.

\section{Stage III}

Stage III is diagnosed when a retrograde wave in the umbilical cord or PI in DV > 95 centile are found. In this case, the risk of intrauterine death is also high $-\mathrm{OR}=7.15$, with a $95 \% \mathrm{Cl}$ of 5.22-9.81. It is optimal to introduce increased cardiotocographic monitoring. Ultrasound examination should be performed in a hospital setting every 12-24 hours. Pregnancy should be ended by caesarean section, after a course of steroid therapy in the event of abnormal cardiotocographic records or persistent flow reversal.

\section{Stage IV}

Stage IV is diagnosed when an absence of A wave, reverse $A$ wave in DV or incorrect values of the CTG records are found. The patient must be hospitalized immediately, be under constant cardiotocographic supervision and should be given steroids. This is an indication for urgent termination of pregnancy by caesarean section.

Regardless of the abnormal values of vascular flow measurements assessed in Doppler examination, an indication for termination of pregnancy is reduced to $<3.5$ short-term variability for $>40$ minutes or repeated decelerations in cardiotocographic tracings [29-31]. The optimal place of hospitalization is a tertiary perinatal care center. Hospitalization is indicated pending results of cardiotocographic tracings, ultrasound assessment, the patient's condition and the coexistence of hypertension and pre-eclampsia indicators. The diagnosis of pre-eclampsia increases the severity of FGR by one level. In case of diagnostic doubts, lack of experience in ultrasound evaluation, or lack of appropriate equipment, it is recommended to refer the patient at any stage of gestation to a reference center or to a perinatal medicine specialist to determine further management.

Hospitalization is indicated in each case of FGR complicated by oligohydramnios (MVP $<2$ or AFI $<5$ ), abnormal biophysical profile, suspicious CTG recording, vaginal bleeding, reduced fetal movements or lack of end-diastolic flow in the umbilical artery.

The assessment of fetal movements after 30 weeks of gestation, according to the PSOGO recommendations, should take place during the periods of fetus' highest activity 
or after main meals (but not within the first hour after eating). The correct value is considered to be at least 4 movements within an hour or 10 movements within two hours [32].

Supervision of fetal well-being during hospitalization in a reference center should be based on recommendations to ensure appropriate supervision, consistent with current medical knowledge.

The route of delivery should always be chosen individually, considering obstetric conditions, risk factors and experience of medical personnel, but also an increased risk of chronic fetal hypoxia in the event of impaired fetal well-being with an indication for caesarean section. After the completion of 37 weeks of gestation, in the presence of indications for its termination and no contraindications to vaginal delivery, it is recommended to induce labor with continuous cardiotocographic monitoring. FGR is a contraindication to vaginal delivery in case of breech position of the fetus. In case of pregnancy with FGR and the need to deliver $<32$ weeks, it is recommended to administer magnesium sulphate (MgSO4) for neuroprotection of the fetus.

\section{Late fetal growth restriction}

In the case of late-onset FGR, the biggest problem is its diagnosis and differentiation between the growth-restricted fetus and a constitutionally small fetus (SGA). The SGA fetus' growth potential is most likely inherited from its parents. Its growth parameters are within 3-10 percentile, but the blood flow in the uterine arteries, the umbilical cord, and the middle cerebral artery is normal. Such fetuses are, in most cases, healthy. Termination of pregnancy should occur at the time of delivery at the latest, in accordance with the PSOGO recommendations on labor induction [33].

Supervision of such fetus requires an evaluation of growth dynamics and the blood flow in the vessels every 2 weeks. In low-risk populations, the number of SGA diagnosed at term does not exceed $15 \%$. In studies involving populations similar to the Polish one, despite of performing the commonly recommended examination between 28 and 32 weeks of gestation, the rate of such fetuses in low-risk pregnancies was 19\%, and in high-risk pregnancies $47 \%$ [10]. Therefore, it is extremely important to select patients who require additional ultrasound examination between 32-40 weeks of gestation.

In late FGR, we rarely observe an abnormal blood flow spectrum in the uterine arteries, but Figueras et al. [27] showed that the evaluation of blood flow in these vessels, also in pregnancies over 32 weeks, allows for identification of fetuses with an increased risk of perinatal complications. In the DIGITAT study, AEDV was found in only $10 \%$ of patients, and the mean PI values in the umbilical cord ranged from 0.93-0.98 [34]. In late FGR, the most useful is the evaluation of CPR or MCA flow, and the values of these parameters $<5$ percentile allow for identification of fetuses in which pregnancy should be terminated earlier [27]. Induction of labor at 37 weeks of gestation is indicated for fetuses with an estimated weight below the $3^{\text {rd }}$ percentile or with an abdominal circumference below the $3^{\text {rd }}$ percentile. Early termination of pregnancy should be considered in the presence of symptoms of pre-eclampsia, depending on the results of cardiotocography and ultrasound examinations. If CPR is $<5^{\text {th }}$ percentile or MCA flow is $<5^{\text {th }}$ percentile, the ductus venous blood flow should be assessed and the management like for early FGR should be introduced. The other indications for hospitalization, CTG surveillance, delivery route, counting fetal movements and assessment of the biophysical profile are the same as in early FGR. Regardless of whether we are dealing with late FGR or SGA, CTG and USG control should be implemented in the event of increased blood pressure, vaginal bleeding, uterine contractions and reduced fetal movements.

\section{Screening tests and and general prevention}

When compiling the management protocols, the authors considered different scenarios depending on whether the patient was screened and/or assessed for FGR risk in the first trimester of pregnancy. The scheme also assumes a situation when, despite the existing indications, the pregnant woman did not receive or did not start taking acetylsalicylic acid. The risk of FGR should be assessed at each stage of pregnancy. Scheme I presents the method of risk evaluation in the first and second trimesters of pregnancy, taking into account the lack of risk assessment based on ultrasound and biochemical parameters in the first trimester. In such case, it should be done based on the previously described risk factors (1A and $1 \mathrm{~B})$.

In a single pregnancy, the Polish Society of Gynecologists and Obstetricians recommends the use of prenatal screening between 11 and $13+6$ weeks of pregnancy to evaluate the risk of early-onset FGR with Doppler evaluation of uterine blood flow (UtA), mean arterial pressure (MAP) and determine the value of placental growth factor (PIGF) in blood. In high-risk situations (> 1:100), it is justified to start the administration of $150 \mathrm{mg}$ of acetylsalicylic acid before 16 weeks of gestation and continue it until the $36^{\text {th }}$ week [14] (Fig. 3).

According to the PSOGO standards, ultrasound examination should be performed at 11-14, 20 and 28-32 weeks of gestation. In a group at high risk of FGR and/or pre-eclampsia identified on the basis of the first trimester screening, a screening between 19-24 weeks of gestation should be considered using the patient's history and UtA PI, MAP, PIGF and sFlt-1 evaluation. Ultrasound assessment of growth should be performed according to the scheme outlined for high-risk pregnancies (High-risk pregnancy management scheme). 


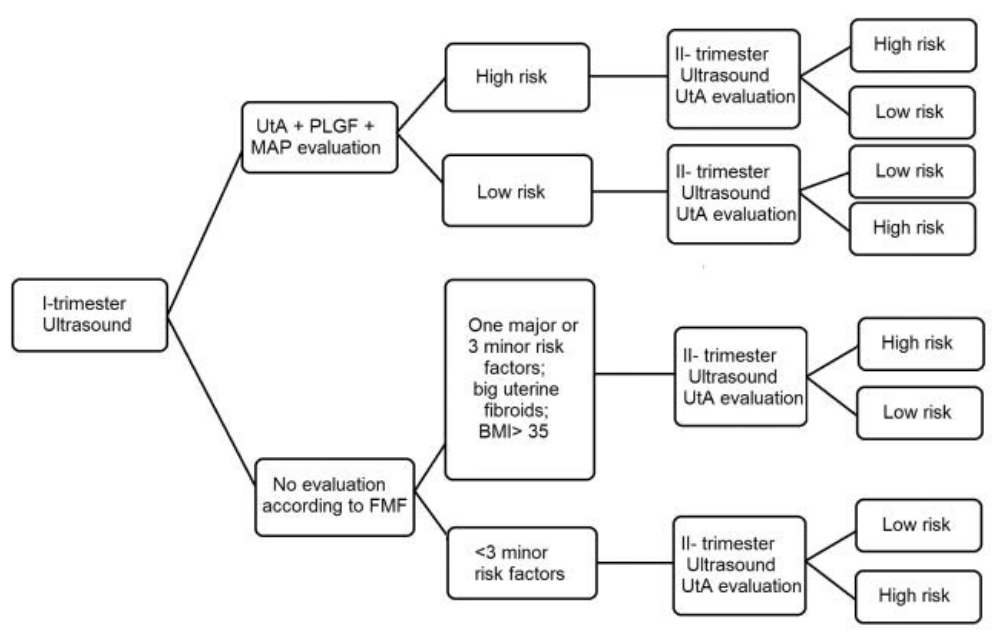

Figure 3. Scheme for risk assessment in the I/II trimester of pregnancy

However, in low-risk pregnancies, it may be considered to evaluate the uterine blood flow in the second and third trimesters. In the case of correct biometry and PI UtA $>95$ th percentile, we recommend an additional control of growth dynamics between 34-38.

Confirming the high risk of early-onset FGR/pre-eclampsia occurrence ( $>1: 100$ ) entails an individualized approach in the form of every-day blood pressure measurements, weekly assessment of proteinuria and periodic evaluation of fetal biometry.

\section{Placenta}

Examination of the placenta: description of macroscopic changes in medical record documentation and possibly a histopathological examination.

\section{REFERENCES}

1. American College of Obstetricians and Gynecologists' Committee on Practice Bulletins-Obstetrics and the Society forMaternal-FetalMedicin. ACOG Practice Bulletin No. 204: Fetal Growth Restriction. Obstet Gynecol. 2019; 133(2): e97-e9e109, doi: 10.1097/AOG.0000000000003070, indexed in Pubmed: 30681542.

2. Figueras F, Gardosi J. Intrauterine growth restriction: new concepts in antenatal surveillance, diagnosis, and management. Am J Obstet Gynecol. 2011; 204(4): 288-300, doi: 10.1016/j.ajog.2010.08.055, indexed in Pubmed: 21215383.

3. Ganzevoort W, Thornton JG, Marlow N, et al. GRIT Study Group, TRUFFLE Study Group. Comparative analysis of 2-year outcomes in GRIT and TRUFFLE trials. Ultrasound Obstet Gynecol. 2020; 55(1): 68-74, doi: 10.1002/uog.20354, indexed in Pubmed: 31125465.

4. Lees CC, Marlow N, van Wassenaer-Leemhuis A, et al. TRUFFLE study group. 2 year neurodevelopmental and intermediate perinatal outcomes in infants with very preterm fetal growth restriction (TRUFFLE): a randomised trial. Lancet. 2015; 385(9983): 2162-2172, doi: 10.1016/S01406736(14)62049-3, indexed in Pubmed: 25747582.

5. Lees C, Marlow N, Arabin B, et al. TRUFFLE Group. Perinatal morbidity and mortality in early-onset fetal growth restriction: cohort outcomes of the trial of randomized umbilical and fetal flow in Europe (TRUFFLE). Ultrasound Obstet Gynecol. 2013; 42(4): 400-408, doi: 10.1002/uog.13190, indexed in Pubmed: 24078432.

6. Hepburn M, Rosenberg K. An audit of the detection and management of small-for-gestational age babies. Br J Obstet Gynaecol. 1986; 93(3):212-216, doi: 10.1111/j.1471-0528.1986.tb07895.x, indexed in Pubmed: 3964595.
7. Backe B, Nakling J. Effectiveness of antenatal care: a population based study. Br J Obstet Gynaecol. 1993; 100(8): 727-732, doi: 10.1111/j.14710528.1993.tb14263.x, indexed in Pubmed: 8399010.

8. Pietryga M, Borowski D, Brązert J, et al. Rekomendacje Sekcji Ultrasonografii Polskiego Towarzystwa Ginekologicznego w zaskresie przesiewowej diagnostyki ultrasonograficznej w ciąży o przebiegu - 2015r. Ginekol Pol. 2015; 86(7): 551-559.

9. Rozporządzenie Ministra Zdrowia z dnia 16 sierpnia 2018 r. w sprawie standardu organizacyjnego opieki okołoporodowej. Dziennik Ustaw Rzeczpospolitej Polskiej poz. 1756.

10. Kajdy A, Modzelewski J, Jakubiak M, et al. Effect of antenatal detection of small-for-gestational-age newborns in a risk stratified retrospective cohort. PLoS One. 2019; 14(10): e0224553, doi: 10.1371/journal. pone.0224553, indexed in Pubmed: 31671164.

11. Ego A, Zeitlin J, Batailler $P$, et al. Stillbirth classification in population-based data and role of fetal growth restriction: the example of RECODE. BMC Pregnancy Childbirth. 2013; 13: 182, doi: 10.1186/14712393-13-182, indexed in Pubmed: 24090495.

12. Gardosi J, Giddings S, Clifford S, et al. Association between reduced stillbirth rates in England and regional uptake of accreditation training in customised fetal growth assessment. BMJ Open. 2013; 3(12): e003942, doi: 10.1136/bmjopen-2013-003942, indexed in Pubmed: 24345900.

13. The Investigation and Management of the Small-for-Gestational-Age Fetus. RCOG Green-top Guideline No. 31: 1-34.

14. Roberge S, Nicolaides K, Demers S, et al. The role of aspirin dose on the prevention of preeclampsia and fetal growth restriction: systematic review and meta-analysis. Am J Obstet Gynecol. 2017; 216(2): 110-120. e6, doi: 10.1016/j.ajog.2016.09.076, indexed in Pubmed: 27640943.

15. Wojtyła A, Goździewska M, Paprzycki P, et al. Tobacco-related Foetal Origin of Adult Diseases Hypothesis--population studies in Poland. Ann Agric Environ Med. 2012; 19(1): 117-128, indexed in Pubmed: 22462456.

16. Salomon LJ, Alfirevic Z, Da Silva Costa F, et al. ISUOG Practice Guidelines: ultrasound assessment of fetal biometry and growth. Ultrasound Obstet Gynecol. 2019; 53(6): 715-723, doi: 10.1002/uog.20272, indexed in Pubmed: 31169958.

17. Dall'Asta A, Girardelli S, Usman S, et al. Etiology and perinatal outcome of periviable fetal growth restriction associated with structural or genetic anomaly. Ultrasound Obstet Gynecol. 2020; 55(3): 368-374, doi: 10.1002/uog.20368, indexed in Pubmed: 31180600.

18. Peyron F, L'ollivier C, Mandelbrot L, et al. Maternal and Congenital Toxoplasmosis: Diagnosis and Treatment Recommendations of a French Multidisciplinary Working Group. Pathogens. 2019; 8(1), doi: 10.3390/pathogens8010024, indexed in Pubmed: 30781652.

19. Conner SN, Longman RE, Cahill AG. The role of ultrasound in the diagnosis of fetal genetic syndromes. Best Pract Res Clin Obstet Gynaecol. 2014; 28(3): 417-428, doi: 10.1016/j.bpobgyn.2014.01.005, indexed in Pubmed: 24534428.

20. Buck Louis GM, Grewal J, Albert PS, et al. Racial/ethnic standards for fetal growth: the NICHD Fetal Growth Studies. Am J Obstet Gynecol. 
2015; 213(4): 449.e1-449.e41, doi: 10.1016/j.ajog.2015.08.032, indexed in Pubmed: 26410205.

21. Gorstein J, Sullivan K, Yip R, et al. Issues in the assessment of nutritional status using anthropometry. Bull World Health Organ. 1994; 72(2): 273-283, indexed in Pubmed: 8205648.

22. Gardosi J. Customised assessment of fetal growth potential: implications for perinatal care. Arch Dis Child Fetal Neonatal Ed. 2012; 97(5): F314-F317, doi: 10.1136/fetalneonatal-2012-301708, indexed in Pubmed: 22684160.

23. Gardosi J. Counterpoint. Am J Obstet Gynecol. 2019; 220(1): 74-82, doi: 10.1016/j.ajog.2018.10.006, indexed in Pubmed: 30315787.

24. Lausman A, Kingdom J, Gagnon R, et al. Intrauterine Growth Restriction: Screening, Diagnosis, and Management. J Obstet Gynaecol Can. 2013; 35(8): 741-748, doi: 10.1016/s1701-2163(15)30865-3.

25. Beune IM, Damhuis SE, Ganzevoort W, et al. Consensus definition of fetal growth restriction: a Delphi procedure. Ultrasound Obstet Gynecol. 2016; 48(3): 333-339, doi: 10.1002/uog.15884, indexed in Pubmed: 26909664.

26. Baschat AA. Planning management and delivery of the growth-restricted fetus. Best Pract Res Clin Obstet Gynaecol. 2018; 49:53-65, doi: 10.1016/j. bpobgyn.2018.02.009, indexed in Pubmed: 29606482.

27. Figueras $F$, Gratacós E. Update on the diagnosis and classification of fetal growth restriction and proposal of a stage-based management protocol. Fetal Diagn Ther. 2014; 36(2): 86-98, doi: 10.1159/000357592, indexed in Pubmed: 24457811.

28. Caradeux J, Martinez-Portilla RJ, Basuki TR, et al. Risk of fetal death in growth-restricted fetuses with umbilical and/or ductus venosus absent or reversed end-diastolic velocities before 34 weeks of gestation: a systematic review and meta-analysis. Am J Obstet Gynecol. 2018; 218(2S): S774-S782.e21, doi: 10.1016/j.ajog.2017.11.566, indexed in Pubmed: 29233550.

29. Ebbing C, Acharya G, Sitras V, Helbig A, Husby H. Intrauterine growth restriction. Approved by the Norwegian Society of Obstetrics and Gynecology, June 2016.

30. Vintzileos AM, Smulian JC. Decelerations, tachycardia, and decreased variability: have we overlooked the significance of longitudinal fetal heart rate changes for detecting intrapartum fetal hypoxia? Am J Obstet Gynecol. 2016; 215(3):261-264, doi: 10.1016/j.ajog.2016.05.046, indexed in Pubmed: 27568857.

31. Martin A. [Fetal heart rate during labour: definitions and interpretation]. J Gynecol Obstet Biol Reprod (Paris). 2008; 37 Suppl 1: S34-S45, doi: 10.1016/j.jgyn.2007.11.009, indexed in Pubmed: 18191915.

32. Postępowanie w nadciśnieniu tętniczym u kobiet w ciąży. Postępowanie w nadciśnieniu tętniczym u kobiet w ciąży. Zapobieganie, diagnostyka, leczenie i odległe rokowanie Stanowisko Polskiego Towarzystwa Nadciśnienia Tętniczego, Polskiego Towarzystwa Kardiologicznego oraz Polskiego Towarzystwa Ginekologów i Położników. Ginekol Perinatol Prakt. 2019; 4(2): 43-111.

33. Bomba-Opoń D, Drews K, Huras H, et al. Polish Gynecological Society Recommendations for Labor Induction. Ginekol Pol. 2017; 88(4): 224-234, doi: 10.5603/GP.a2017.0043, indexed in Pubmed: 28509326.

34. Boers KE, Vijgen SMC, Bijlenga D, et al. DIGITAT study group. Induction versus expectant monitoring for intrauterine growth restriction at term: randomised equivalence trial (DIGITAT). BMJ. 2010; 341: c7087, doi: 10.1136/bmj.c7087, indexed in Pubmed: 21177352. 